\title{
1 LA-ICP-MS chemical analysis of archaeological otoliths as a tool for \\ 2 seasonality and site catchment studies
}

3

4 Evan Peacock $^{\mathrm{a} *}$, Rinat Gabitov ${ }^{\mathrm{b}}$, Jonathan R. Frisch ${ }^{\mathrm{c}}$, Carla S. Hadden ${ }^{\mathrm{d}}$, Bradley Carlock ${ }^{\mathrm{a}}$,

5 Kate L. Henderson ${ }^{\text {e }}$

6

$7 \quad{ }^{a}$ Department of Anthropology \& Middle Eastern Cultures, PO Box AR, Mississippi State, MS 39762, United States

$8 \quad$ bepartment of Geosciences, PO Box 54458, Mississippi State, MS 39762, United States

$9 \quad{ }^{\mathrm{c}}$ Department of Chemistry, University of Wisconsin-Stout, 712 South Broadway St., Menomonie, WI 54751, United 10 States

11 dGeorgia Museum of Natural History, 101 Cedar St., Athens, GA 30602, United States

$12 \quad{ }^{\mathrm{e}}$ Department of Biochemistry

13 University of Wisconsin-Madison, 433 Babcock Drive, Madison WI 53706, United States

14

$15 *$ Corresponding author.

16 E-mail address: peacock@anthro.msstate.edu

17

A B S T R A C T

20 Analysis of the trace element chemistry of otoliths via Laser Ablation-Inductively Coupled

21 Plasma-Mass Spectrometry (LA-ICP-MS) has become common in fisheries-related work,

22 allowing biologists to trace connectivity between habitats over the life cycles of fish. For

23 archaeological specimens, elements from the outer edges of archaeological otoliths have the

24 potential to provide information on site seasonality complementary to oxygen isotope data; they 
25 also may inform on place of capture of fish, thus elucidating exploited ranges and/or social and

26 economic links between settlements. Adopting this method will require careful consideration of a

27 number of complicating factors related to metabolic processes affecting otolith production,

28 analytical procedures peculiar to LA-ICP-MS, and diagenesis, in addition to the usual

29 complications of species identification and assessment of sample adequacy. Here, we review

30 such factors as they affect the utility of the method for sourcing and seasonality research with

31 archaeological otoliths, using the results of a pilot study of specimens from two Woodland-

32 period sites in coastal Alabama, southeastern USA, to illustrate the potential and the current

33 limitations of the method for archaeological research.

Keywords: otoliths, LA-ICP-MS, trace elements, oxygen isotopes, site catchment, seasonality

\section{Introduction}

The last quarter-century has seen an explosion of fisheries-related work using otolith (fish “earstone”) chemistry (e.g., Hamilton and Warner 2009; López-Duarte et al. 2012; Ramsay et al.

41 2011; Thorrold et al. 1998; Weber et al. 2002). Such work is predicated upon several useful

42 properties of otoliths relative to other biological structures: 1) otoliths begin growing during the

43 larval stage and growth continues throughout the life of the fish; 2) growth is expressed in

44 incremental bands representing short-term (even daily) periods; 3) otoliths are acellular and

45 metabolically inert, meaning that, once formed, they are not resorbed or otherwise chemically

46 altered via biogenic processes (e.g., Ramsay et al. 2011); and 4) otolith chemistry represents, to

47 some degree, the chemical composition of the waters in which fish live over the course of their 
48 lives. These characteristics combine to make otoliths particularly useful structures for

49 determining fish natal habitats and connectivity, the exchange of individuals over habitat patches

50 over time (López-Duarte et al. 2012), and such information lends itself to range-scale

51 management practices.

52 For archaeology, information on otolith chemistry can be applied in two ways: 1) as a

53 method of determining site seasonality that is complementary to $\mathrm{O}$ isotope and other traditional

54 forms of seasonality assessment (Andrews et al. 2003; Saunders et al. 2005); and 2) establishing

55 catchment, or the geographic range over which fish were harvested in the past (Disspain, Ulm,

56 and Gillanders 2015). Before either of these applications can be realized, however, the many

57 variables affecting otolith chemistry and those arising from different analytical methods must be

58 recognized (Disspain, Ulm, and Gillanders 2015) and formal procedures established to control

59 for those variables as much as possible. In this paper we discuss such variables, using data from

60 a pilot study of otoliths from two coastal sites in the southeastern USA to illustrate both the

61 promise of otolith chemical data for archaeology and the complications that analysts will face as

62 they try to obtain such data and put them to use.

63

64

65

66

67

68

69

70

\section{Sources of Variation in Otolith Chemistry}

The basis for both modern and archaeological applications of otolith chemistry is the assumption that environmental differences over space are reflected in different elemental concentrations in water bodies, which in turn are reflected in otoliths, yielding information on spawning locales, point of capture, and any seasonal movement between. In a word, chemical "fingerprinting" of individual fish and/or species. In practice, there are a large number of factors that influence the incorporation of major ( 1 wt. \% or more), minor ( $>100 \mathrm{ppm})$ and trace ( $<100$ 
$71 \mathrm{ppm}$ ) elements in otoliths, so the relationship between water chemistry and otolith chemical

72 composition is not a direct one. Disspain, Ulm, and Gillanders (2015) have recently published a

73 valuable overview related to this topic; we refer readers to their article for additional coverage of

74 this topic and some interesting site-specific examples.

75 Otoliths are structures within the inner ear of vertebrates that function to help maintain

76 balance (motion and orientation to gravity). In bony fishes, otoliths "float" behind the brain, at

77 the back of the fish's cranium. They are surrounded by a fluid called the endolymph. Elements

78 are incorporated into otoliths as they crystallize. There are three kinds of otolith: the sagita, the

79 lapillus, and the asteriscus. Sagittae are preferentially used for time-dependent environmental

80 tracking and paleoclimatic work due to larger size and formation at an early life stage (e.g., Hoff

81 et al. 1997). All otoliths are calcium carbonate; asteriscii are vateritic, while the other two kinds

82 are aragonitic. An important constituent is protein, which comprises from $1-8 \%$ of otoliths

83 depending on species, with around 3 - 4\% being a common amount (Campana 1999:265).

84 Water-insoluble proteins (a.k.a. "otolin" - Degens et al. 1969) make up about half the protein

85 present and provide the "structural framework" for calcification, while calcification rate is partly

86 regulated by the remaining, water-soluble proteins (Campana 1999:265) and by temperature. The

87 full effects of temperature on otolith formation are incompletely understood, but elements known

88 to be affected include Mg, U, Na, K, Mn, Zn and Fe (Campana 1999). While some authors have

89 seemingly detected a correlation between temperature and Sr incorporation in otoliths (e.g., Bath

90 et al. 2000), Campana (1999:273) reviewed a large number of case studies and found no

91 consistent relationship in this regard, except in very cold $\left(<10^{\circ} \mathrm{C}\right)$ water. Sr concentrations are,

92 however, affected by salinity (Campana 1999:267, 274; see also Kalish 1989). 
Elemental impurities in the otolith matrix can occur "within the crystal lattice as a [ionic]

94 substitute for calcium, as an inclusion in the interstitial spaces, or in association with the

95 proteinaceous matrix” (Campana 1999:266). Precipitation of other carbonates, such as $\mathrm{SrCO}_{3}$, is

96 a less likely source of elemental inclusion than is ion substitution, which favors $\mathrm{Sr}$, Mg, and Ba

97 ions that have the same charge as $\mathrm{Ca}(2+)$ and ionic radii deviating from Ca by less than $25 \%$

98 (Campana 1999:266; Ramsay et al. 2011:831; Gaetani and Cohen 2006: 4617) and that are

consequently bound into the crystal lattice. Among these elements, Sr has the most similar radius

100 to $\mathrm{Ca}$, while $\mathrm{Mg}$ and $\mathrm{Ba}$ are smaller and larger, respectively. On the other hand, elemental

101 inclusions in interstitial spaces such as the "micro-channels" typical of otolith architecture are

102 relatively poorly bound, so that elements such as $\mathrm{Na}, \mathrm{Cl}, \mathrm{Zn}$ and $\mathrm{K}$ are easily leached out

103 (Campana 1999:266).

104

A major consideration in understanding the relative availability of elements for inclusion in

105 otoliths is bioregulation (Bath et al. 2000:1705; Campana et al. 1994:1949; Kalish 1991). Fish take up elements via the gills; these are then passed into the blood plasma, from there into the

107 endolymph, and from there into the crystallizing otolith (Campana 1999:266-267). There are

108 various complicating factors in this process. For one, blood plasma chemistry can vary

109 seasonally with temperature (Kalish 1991), a factor that likely is species-specific. Another

110 complicating factor is osmoregulation, the maintenance of water levels in an organism. In fish,

111 osmoregulatory processes "level out” the concentrations of elements such as $\mathrm{Ca}, \mathrm{Na}, \mathrm{K}, \mathrm{Mg}, \mathrm{Cl}$,

112 P, Cu, and S, even between fresh and saltwater environments (Campana 1999:268-269).

113 Accordingly, "it is clearly unrealistic to expect the otolith content of physiologically regulated

114 elements to reflect environmental abundance” (Campana 1999:269). Elements found in otoliths

115 that are relatively unregulated, and therefore expected to more closely reflect environmental 
116 loads, include Sr, Zn, Pb, Mn, Ba and Fe (Elsdon and Gillanders 2003; Campana 1999:269;

117 Hamilton and Warner 2009; see also Disspain, Wilson, and Gillanders 2012). Campana

118 (1999:269-270) also mentions Li, Cd, Ni and the “less abundant” elements as possibly falling

119 into this category, although he notes that, with the exception of Sr, element:calcium ratios in

120 blood plasma will be higher than in the otolith, "indicating that the otolith composition is not

121 merely a passive reflection of plasma composition, even if correlated.” Some elements are then

122 barred or taken up selectively from the blood plasma into the endolymph, "resulting in an

123 endolymph concentration which is depleted in all major ions other than K” (Campana 1999:267).

124 The otolith thus reflects the chemical composition of the endolymph more so than that of the 125 aquatic environment.

126 Beyond uptake via the gills, some elemental contributions to otoliths come from drinking 127 water (especially marine fish, which drink continually) and from food, although this contribution 128 appears to be relatively low (e.g., ca. 10 - 20\% of Ca and Sr for freshwater fishes - Campana 129 1999:267). Obviously, this can vary by species, and may vary seasonally by sex; for example, 130 Mendoza-Carranza (2003) found that during the rainy season, male gafftopsail catfish (Bagre 131 marinus) in near-shore waters consumed significantly more prey fish than did females.

132 Sr is recognized as the best marker for source (e.g., Ludsin et al. 2006; Pontual et al. 2000), 133 especially for anadromous fish (Campana 1999; see also Disspain, Ulm, and Gillanders 2015), 134 because: 1) it is the least-regulated element; 2) there is a purported lack of a temperature effect 135 on Sr uptake (Campana 1999); and 3) differences in concentration between fresh and salt water 136 (lower Sr:Ca in the former - Hale and Swearer 2008; Pontual et al. 2000) can be quite abrupt, 137 (Hamilton et al. 2009), reflecting the $30-35 \%$ difference in salinity between the two 138 environments. However, differences in Sr:Ca ratios between species, even those habitually 
139 occupying the same areas, may be expected, as will be an increase in Sr:Ca with the age of the 140 fish (Campana 1999; Hamilton et al. 2009). This latter effect probably is related to the rate of 141 protein synthesis (Kalish 1989), which in turn affects the rate of crystallization of the otolith 142 (Campana 1999:2740), which generally slows with age (Chang et al. 2012). Ramsay et al. (2011) 143 were able to correct for the effects of otolith size via regression analysis, with data showing 144 linear relationships; however, Thorrold et al. (1998:258) found “lower levels of most elemental 145 and isotopic variables with increasing otolith weight,” an age-related effect that was not 146 systematic enough to allow for mathematical correction. Such differences between studies likely 147 reflect species-level variability. Elemental differences also can be expected with major 148 ontogenetic phase shifts, such as the period of larval metamorphosis into juvenile stage 149 (Hamilton et al. 2009:242; Mugiya and Satoh 1995; Swearer 2000). Environmental variability, while the very basis for how otoliths can be used in sourcing 151 studies, is at the same time another area of concern. Major differences between marine and 152 freshwater systems are primarily found in the common marine salts (Campana 1999:271). 153 However, Sr (or any other chemical) loads are not consistent in stream discharge or in ocean 154 basins over time due to "upwelling, volcanic activity, pollution, biological activity, and inter155 annual differences” that can “act to confound any expected [chemical] relationship” between 156 source water and otolith chemistry on a one-to-one basis” (Campana 1999:271). Water depth is 157 another factor influencing chemical availability, with some elements (e.g., Ba, Zn, Cd) showing 158 enrichment at greater depth in the ocean (Campana 1999:267).

159 Other factors that can influence elemental uptake include $\mathrm{pH}$ and dissolved $\mathrm{O}$ concentration 160 of water (Campana 1999:267), side of the fish (Campana 1999:283; Thresher et al. 1994; but see 161 Andrus and Crowe 2002; Campana et al. 1994; Proctor and Thresher 1998), and 
162 part of the otolith sampled (e.g., Pontual et al. 2000). Given all the above caveats, Campana’s

163 (1999:271) cautionary observation, "Do the elemental concentrations in the otolith reflect the

164 elemental concentrations of the ambient water? The answer is an unequivocal 'sometimes'," is

165 certainly warranted, especially given the additional complications arising from sampling choices, 166 analytical protocols, and the vagaries of archaeological material. We discuss these below within

167 the context of a pilot study designed to explore seasonality and chemical fingerprinting using 168 archaeological otoliths.

\section{A Pilot Study from the Northern Coast of the Gulf of Mexico: Sites and Expectations}

To explore the potential for trace elemental analysis of archaeological specimens to

172 contribute to studies of site seasonality and catchment area, we analyzed twelve sea catfish

173 otoliths from pit features at two Woodland-period sites on the coast of Alabama. Plash Island

174 (1BA134) is primarily a late Middle Woodland-period site (A.D. 325-640) with minor later

175 occupation. The Bayou St. John, or Orange Beach site, is a primarily Late Woodland-period site

176 (A.D. 650-1040) with minor earlier and later occupation (Reitz et al. 2013). Reitz et al. (2013)

177 provide details about the sites, contexts, and specimens. Although the sites are only about $25 \mathrm{~km}$

178 distant from one another as the crow flies, different water chemistry can be expected due to the

179 drainages represented. Plash Island is located on the northern edge of Bon Secour Bay, an eastward extension of Mobile Bay. The Alabama River feeds the bay, representing a very large

181 drainage incorporating several different physiographic provinces and associated geological

182 substrates and soil types. The Bayou St. John site is located on the southwest part of Perdido Bay

183 (Figure 1), which receives water from the Conecuh River, a much smaller stream geographically 184 restricted to the Coastal Plain. 
In fisheries research, otoliths often are analyzed via whole-sample, solution-based methods.

While this is particularly useful for the chemical analysis of larval otoliths to characterize natal areas, it sacrifices the time-dependent chemical series represented in growth bands developed later in life (Campana 1999:282-283; Chang et al. 2012; Jones and Chen 2003). An increasingly popular set of methods involves the use of beams, especially lasers, to obtain chemical data from different parts of the otolith. Chief among these methods is Laser Ablation-Inductively Coupled Plasma-Mass Spectrometry (LA-ICP-MS) (e.g., Barnett-Johnson et al. 2005; Campana et al. 1994; Chang et al. 2012; Ludsin et al. 2006; Pontual et al. 2000). LA-ICP-MS has seen increasing use in archaeological research over the last several years (e.g., Speakman and Neff 2005), including work on zooarchaeological remains (e.g., Peacock et al. 2010). There are good reasons for the popularity of the method, including minimal sample preparation, high sensitivity, rapid acquisition of multi-elemental data, isotopic discrimination, and targeted data acquisition due to high spatial resolution (typically 20 - 40 microns for carbonate minerals) (Resano et al. 2009:1). We used LA-ICP-MS to address questions of source water chemistry and seasonality, drawing upon the appropriate fisheries literature to set our analytical parameters.

Any chemical differences between the two sets of specimens hypothetically represent different chemistry of the source waters. For example, Reitz et al. (2013) found, on average, more negative $\delta^{18} \mathrm{O}$ values in shells and otoliths from the Plash Island site as compared to specimens from Bayou St. John, a result probably due to the greater amount of freshwater entering Mobile Bay. For this question, we restrict our discussion to data obtained from the first laser raster line (i.e., from near the outer edge) on each otolith. We expected to see differences between sample sites via an ordination approach using elements that fell above detection limits. In terms of seasonality, deriving expectations from the literature for most trace elements is not 
208 straightforward. Ba, for example, should increase near river sources (Hamilton et al. 2008, and 209 references therein), yet also follows a nutrient-style profile in that it increases with water depth 210 (Campana 1999; Hamilton et al. 2009). Thus, although Ba can readily substitute for Ca in the 211 crystalline matrix of otoliths, it can be obtained from different habitats at different times of the 212 year, depending on the habits of the fish species involved. The same caveat applies to Sn and Cd 213 (Campana 1999:271). As noted above, Na, Cl, Zn and K are easily leached (Campana 1999:266), 214 making them less-than-desirable elements for archaeological specimens. Ba and Zn often show 215 low detection and poor precision in LA-ICP-MS testing of otolith lab standards (e.g., Thorrold et 216 al. 1998) but sometimes work well (e.g., Ludsin et al. 2006); the causes of such variability 217 currently are poorly known. For both areas of inquiry, the most reasonable expectation concerns 218 Sr, which should decrease with freshwater input (e.g., Pontual et al. 2000:499). Sr levels revealed 219 via LA-ICP-MS should mirror the seasonal rise-and-fall patterns noted in $\delta^{18} \mathrm{O}$ values in otoliths 220 (Reitz et al. 2013).

221 We stress here that our work is exploratory in nature: we did not try to address all of the 222 complicating issues discussed earlier, many of which also are discussed by Disspain, Ulm, and 223 Gillanders (2015). We merely wished to investigate whether, given a set of protocols for LA224 ICP-MS analysis derived from the fisheries literature, correspondences between sites and otolith 225 chemistry and/or between trace elements and light isotopes from the same specimens existed in 226 our study area. For other work involving season and place of capture as derived from LA-ICP227 MS analysis of archaeological otoliths, see Disspain, Wilson, and Gillanders (2012). 
One problem with archaeological specimens is identification, which will be more or less 231 difficult depending on species (e.g., Chen et al. 2011; see also Disspain, Ulm, and Gillanders 232 2015) and preservation state. Two species of sea catfish, the gafftopsail catfish Bagre marinus 233 and the hardhead catfish Ariopsis felis, are confidently represented in the twelve otoliths we 234 analyzed for trace elements, but some specimens could be one or the other, and these were 235 accordingly identified only to the family level (Ariidae) (Table 1). Both B. marinus and A. felis 236 spawn in inshore waters in the summer months and move to deeper water in the winter, although 237 some fish may be found near-shore year-round (e.g., Mendoza-Carranza 2003).

\begin{tabular}{|l|l|l|}
\hline \multicolumn{2}{|l|}{ Table 1. Otoliths used in both LA-ICP-MS elemental analysis and oxygen isotope analysis. } \\
\hline Heorgia Museum of Natural & Archaeological Site & Species \\
\hline 2600469.A & & \\
\hline 2600470.A & Plash Island & Ariopsis felis \\
\hline 2600019.B & Plash Island & Bagre marinus \\
\hline 2600021.A & Plash Island & Bagre marinus \\
\hline 2600020.B & Plash Island & Ariidae \\
\hline 2600418.A & Plash Island & Ariopsis felis \\
\hline 2600517.A & Plash Island & Ariopsis felis \\
\hline 2600017.B & Plash Island & Ariidae \\
\hline 2600018.A & Plash Island & Ariopsis felis \\
\hline 2560147.A & Plash Island & Bagre marinus \\
\hline 2560217.B & Bayou St. John & Bagre marinus \\
\hline & Bayou St. John & Ariidae \\
\hline
\end{tabular}


2560215.A

Bayou St. John

Ariopsis felis

Another problem is post-depositional chemical alteration (Andrus and Crowe 2002;

Disspain, Ulm, and Gillanders 2015). While chemical change may be detected via microscopy or cathodoluminescence showing conversion of the unstable polymorph aragonite to calcite over time (Campana 1999:265; Collins 2012), this may not aid in the detection of contamination in the interstitial spaces provided by the microchannel architecture of otoliths. Similar to chemical contamination, the effects of leaching will be hard to determine. In addition, there may well be significant pre-depositional alteration of otoliths due to burning (Andrus and Crowe 2002), smoking, or other preservation/preparation practices. Visually sorting out burned or otherwise obviously modified otoliths (Andrus and Crowe 2002; Disspain, Ulm, and Gillanders 2015) is necessary. Our specimens appeared relatively young and well-preserved (e.g., did not appear "chalky," burned, or discolored). mounted to petrographic slides using Crystalbond thermal adhesive, bi-sectioned through the 253 core, and polished to reveal inner growth bands. Slide-mounted specimens were micromilled 254 using a Merchantek/New Wave computer-controlled 3-D micromill. Between 17 and 22 sample 255 lines were milled for each otolith; the first sample line was along the edge of the otolith, and 256 subsequent lines were spaced at 50- $\mu \mathrm{m}$ intervals following the growth geometry of the otolith. 257 Samples were analyzed on a Thermo Gas Bench II coupled to a Thermo Delta Plus and/or a 258 Thermo Delta V isotope ratio mass spectrometer (IRMS) at the University of Alabama Stable 259 Isotope Lab. All samples were run with NBS-19 standard (in literature also referred to as TSLimestone) so the final results could be expressed in parts per mil (\%) relative to the Vienna 
261 Pee Dee Belemnite (VPDB) international standard. Precision, based on similar analyses in the

262 past, is typically about $0.08 \%$ for $\delta^{13} \mathrm{C}$ and $0.1 \%$ for $\delta^{18} \mathrm{O}$. The NBS-19 analyses also were used

263 to assess and correct, if necessary, for drift and linearity on each sample run (Reitz et al.

264 2013:30).

265 LA-ICP-MS analysis was subsequently conducted using the same specimens. Protocols were 266 derived from a number of papers originating in fisheries work (e.g., Barnett-Johnson et al. 2005;

267 Campana 1999; Campana et al. 1994; Chang et al. 2012; Cook 2011; de Pontual et al. 2000;

268 Hamilton and Warner 2009; Jones and Chen 2003; Ludsen et al. 2006; Ramsay et al. 2011;

269 Sturm 2008; Thorrold et al. 1998). The instrument used was a New Wave Research UP-213

270 Laser Ablation unit coupled to a Perkin Elmer Elan DRC II mass spectrometer, housed in the

271 Department of Chemistry at Mississippi State University.

272 Determination and availability of suitable matrix-matched standards for calibration has been

273 described as the “Achilles heel” of LA-ICP-MS (Resano et al. 2009:13), and this problem has

274 been noted specifically for the analysis of otoliths by many authors (e.g., Campana 1999:283-

275 284; Jones and Chen 2003:433; Portual et al. 2000). Many researchers have relied upon

276 commercially available NIST glasses (e.g., Hamilton and Warner 2009; Chang et al. 2012),

277 while others have used chemically characterized, ground-and-pelleted otoliths (e.g., Chang et al.

278 2012) as standards. As Campana (1999:284) points out, the lack of a commonly-used standard

279 material makes comparison of published data sets difficult. For our study, calcite reference

280 materials were used to test the calibration curves of the instrument. $\mathrm{Mg} / \mathrm{Ca}$ and $\mathrm{Sr} / \mathrm{Ca}$ in those

281 standards (NBS-19, Blue-CC, OKA) were determined independently by isotope dilution ICP-MS

282 and published in Gabitov et al. (2013). Elemental ratios of $\mathrm{Mg} / \mathrm{Ca}$, Sr/Ca, and $\mathrm{Ba} / \mathrm{Ca}$ were

283 determined using Blue-CC standard, the best match for measured elemental ratios in otoliths. 
284 LA-ICP-MS intensity ratios ${ }^{24} \mathrm{Mg} /{ }^{44} \mathrm{Ca},{ }^{88} \mathrm{Sr} /{ }^{44} \mathrm{Ca}$ and ${ }^{138} \mathrm{Ba} /{ }^{44} \mathrm{Ca}$ were normalized to those where $285 \mathrm{Mg} / \mathrm{Ca}=3.62 \mathrm{mmol} / \mathrm{mol}$ (millimole of $\mathrm{Mg}$ per mole of $\mathrm{Ca}$ ), $\mathrm{Sr} / \mathrm{Ca}=0.605 \mathrm{mmol} / \mathrm{mol}$, and $286 \mathrm{Ba}=1.17 \cdot 10^{-2} \mathrm{mmol} / \mathrm{mol}$. Standard deviations between nine individual measurements on 287 carbonate reference material were 15, 16, and $28 \%$ for $\mathrm{Mg} / \mathrm{Ca}, \mathrm{Sr} / \mathrm{Ca}$, and $\mathrm{Ba} / \mathrm{Ca}$ respectively. 288 Those errors are significantly larger than those published in Gabitov et al. (2013), but smaller 289 than observed heterogeneity in otoliths. Due to the lack of a Na carbonate standard, ${ }^{23} \mathrm{Na} /{ }^{44} \mathrm{Ca}$ 290 was used for comparison between different samples. Blanks were run before each otolith and 291 standards before and after each otolith. ${ }^{44}$ Ca was used as an internal standard.

Cleaning of modern otoliths prior to ablation typically is a complicated affair involving a series of washes, sonication, use of clean rooms, etc. (e.g., Campana 1999; Chang et al. 2012;

294 Hamilton and Warner 2009; Ludsin et al. 2006). These practices are primarily related to the 295 removal of any adhering biological material and/or contaminants from sample preparation, such 296 as sectioning or grinding. For our archaeological specimens, two pre-ablation passes were made 297 to remove surface contaminants that might have remained from micromilling or other external 298 sources.

299 An omnipresent problem with LA-ICP-MS is instrumental drift (Campana et al. 1994). As Jones and Chen (2003:433) put it, "lasers provide a transient signal that is not stable. Because of 301 this instability, relative standard deviation (RSD) can be as high as 59\% depending on the 302 structure of the sample surface with up to 25\% RSD using calibration standards.” Pontual et al. 303 (2000:505) noted “poor consistency between [analytical] sessions for some elements,” a 304 phenomenon “clearly related to the apparatus calibration procedure.” Campana et al. (1994) also 305 discuss the effects of operating conditions on analytical results, noting, for example, large, abrupt 306 shifts in elemental levels associated with shutting down of the plasma torch during breaks. They 
caution that "It is important to note that the magnitude of the isotope concentration shifts associated with the [LA]ICPMS far exceeded the sample-to-sample or stock-to-stock variability” (Campana et al. 1994:1946). Results also are conditioned by a host of choices relating to analytical protocols, such as beam width, run time, laser frequency, pulse rate, spot or raster pattern, etc. (see also Campana 1999; Resano et al. 2009). While small beam widths (e.g., 10 $\mu \mathrm{m})$ can yield data from shorter periods of growth (one to a few days), more elements will be below detection limits (e.g., Chang et al. 2012), so there is tradeoff between temporal precision

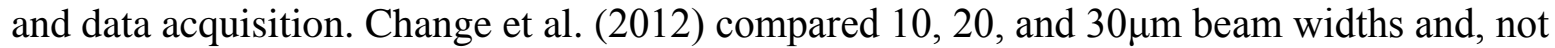
surprisingly, obtained the best results with the largest width, which they estimated represented 30-45 days of growth for hake (Merluccius merluccius). (Interestingly, the effect varied by suites of elements in fish from different water bodies-Chang et al. 2012). Still other sources of analytical noise are the buildup of ablated material in the machine (e.g., Ca accumulation on the skimmer cones - Campana et al. 1994), which necessitates frequent cleaning, and isotopic interference of ${ }^{40} \mathrm{Ca}$ with ${ }^{40} \mathrm{Ar}$ in the carrier gas (e.g., Barnett-Johnson et al. 2005), which limits the choice of analytes.

For our study, the equipment was calibrated daily and sample order alternated between sites. Line interval was set at $50 \mu \mathrm{m}$, with the number of lines set to correspond with the micromilled part of the otolith previously excavated for light isotope analysis (Reitz et al. 2013). The laser raster was set to $500 \mu \mathrm{m}$-long lines running parallel with the micromilled lines. This correspondence is approximate, however, as magnification was too high to allow exact matching of raster lines and micromill channels to be made, a problem that may be correctable in future comparative work by staining of milled specimens or shading via directed light. Given that the fish were relatively young (Reitz et al. 2013), and therefore fast-growing, the initial (outer) raster 
330 line should produce data representing chemical inputs from the waters where the fish were

331 captured. Laser run time was 50 seconds. Scan speed was $10 \mu \mathrm{m} \mathrm{sec}{ }^{-1}$. Laser intensity was set at

$33250 \%$. Beam width was $30 \mu \mathrm{m}$. Frequency was $5 \mathrm{~Hz}$, pulse was $45 \mathrm{~mJ}$, and argon flow rate was

$3331.5{\mathrm{~L}-\mathrm{min}^{-1}}^{-1}$ Level of detection was set at 3 standard deviations (s.d.) above background.

334 Elements initially recorded were ${ }^{238} \mathrm{U},{ }^{208} \mathrm{~Pb},{ }^{138} \mathrm{Ba},{ }^{137} \mathrm{Ba},{ }^{24} \mathrm{Mg},{ }^{87} \mathrm{Sr},{ }^{88} \mathrm{Sr},{ }^{86} \mathrm{Sr},{ }^{55} \mathrm{Mn},{ }^{23} \mathrm{Na}, \mathrm{K}$,

$335 \quad{ }^{57} \mathrm{Fe},{ }^{54} \mathrm{Fe},{ }^{85} \mathrm{Rb},{ }^{118} \mathrm{Sn},{ }^{66} \mathrm{Zn},{ }^{42} \mathrm{Ca},{ }^{43} \mathrm{Ca},{ }^{48} \mathrm{Ca},{ }^{7} \mathrm{Li},{ }^{28} \mathrm{Si},{ }^{59} \mathrm{Co}$, and ${ }^{63} \mathrm{Cu}$. Including standards,

336 blanks, and individual raster lines on otoliths, 305 sample datasets were obtained. The full data

337 set is available upon request to the second author.

338

339

\section{Results}

Only four elements ( $\mathrm{Sr}, \mathrm{Na}, \mathrm{Mg}$ and $\mathrm{Ba}$ ) were consistently noted in sufficient abundance to

341 be used in multivariate analysis. For investigation of chemical makeup related to source area, the

342 data were analyzed via ordination, which positions sites (or specimens) along axes of variation

343 (gradients) drawn through multi-dimensional space. A number or ordination methods are

344 routinely used for exploratory purposes in ecology and palaeoecology, for a variety of data types

345 (including chemical data—see Legendre and Birks 2012). These include principal components

346 analysis (PCA), correspondence analysis (CA), principal coordinates analysis (PCoA), non-

347 metric multidimensional scaling (NMDS), and derivations thereof. Ordination also is used in

348 archaeology, usually for archaeobotanical (e.g., Valamoti and Jones 2003) or zooarchaeological

349 (e.g., Peacock 2002) data, although it is seeing increasing use in the display of artifactual data

350 such as pottery types (e.g., Nance et al. 2013; Ramenofsky et al. 2009; Smith and Neiman 2007).

351 Choosing the proper ordination techniques in ecological studies involves consideration of factors 
352 for which there may be no clear analog in archaeological work, or for which the rationale for 353 particular choices may not be apparent.

Because we are not employing environmental variables matched to the chemical data, ours

355 is an indirect gradient analysis. Using the program PC-Ord (McCune and Mefford 2011), we

356 chose to use Bray-Curtis (polar) ordination, a distance-based (rather than eigen-based) technique

357 via which endpoints represent the extremes in the data, with all other samples defined relative to 358 the endpoints (Rossi 2010). While both Jackson (1993:16) and Oksanen (2013) note that

359 basically similar results may be obtainable with Euclidean and Bray-Curtis solutions, polar 360 ordination is suitable for either qualitative or quantitative data, works for either linear (short, 361 trending) or unimodal (long, Gaussian-curve) gradients, and the results are amongst the easiest to 362 visualize (Rossi 2010). We use the Sørenson distance measurement to dampen the effects of 363 single, large differences in the data (Jackson 1993:12; Oksanen 2013:5). No downweighting of 364 rare (low abundance) elements or other adjustments were made.

365 Analysis was first run using all twelve specimens, using data from the outermost raster line 366 of each otolith to approximate the environment of the capture locale. Although two of the three 367 Bayou St. John specimens are negative along the two major axes of variation (Axis $1=88.48 \%$ 368 of the variation, Axis $2=8.8 \%$ of the variation, cumulative value of $97.34 \%$ ), no real patterns 369 emerge in the data (Figure 2). While all elements are contributing to the distribution of 370 specimens, Sr has the most effect along both Axis $1(r=.986)$ and Axis $2(r=.601)$. The other 371 elements in order of contribution to the distribution are $\mathrm{Na}(.742 \%$ along Axis 1$)$ and $\mathrm{Mg}(\mathrm{r}=$ 372.680 along Axis 2). Ba had little effect along either axis.

373 The lack of any coherent pattern (e.g., clear separation of Plash Island vs. Bayou St. John) 374 likely results from variability arising from a number of sources, including species differences, 
375 seasonal variation, inter-annual variation, minor variations in equipment operation, and other

376 sources of noise as discussed above. Accordingly, although sample size is quite small, we reran

377 the analysis using just the specimens identified as A. felis (4 from Plash Island, 1 from Bayou St.

378 John) (Figure 3). In this case, the one specimen from Bayou St. John was distinguishable from

379 the Plash Island specimens, being the only one to be negative along Axis 2. The major

380 contributor to this placement along Axis 2 is $\mathrm{Na}(\mathrm{r}=.600)$. It is Axis 1 that accounts for most of

381 the variation in the data set, however (95.61\% of the total variance), so the relative placement of

382 specimens along Axis 2 (3.72\% of the variance, 99.33\% cumulative) may be of little

383 consequence. Again, the major contributor to Axis 1 distributions is $\operatorname{Sr}(r=1.000)$, followed by

$384 \mathrm{Ba}(\mathrm{r}=.922), \mathrm{Mg}(\mathrm{r}=.814)$, and $\mathrm{Na}(\mathrm{r}=.874)$. Three of the four Plash Island samples are

385 relatively high in $\mathrm{Na}$, while one Plash Island and the Bayou St. John otolith are low in Na. Sr and

386 Mg show similar distributions across all specimens, while Ba varies inversely with those two

387 elements.

Results were mixed in terms of seasonality, for which we used element:Ca profiles from the

389 full set of raster lines in order to obtain a temporal sequence from each otolith. The O isotope

390 data for each otolith were plotted in order of ontogeny; these are referred to as the isotope

391 "profiles." Season-of-death was determined from the profiles following methods detailed by

392 Colaninno (2012). In the graphs, the outer edge of the otolith is on the left; as noted above, the

393 mill lines for O isotope samples and the laser raster lines are not precisely matched, so

394 comparison of the curves is necessarily approximate. In some cases, what appear to be clear

395 seasonal trends occur that are consistent with the O isotope data (Reitz et al. 2013). Two

396 examples are given here, both of which represent A. felis. The first specimen, GMNH 2560215.A

397 from Bayou St. John, shows a $\delta^{18} \mathrm{O}$ profile typical of summer capture (Figure 4). As expected, 
the Sr:Ca profile shows lower Sr concentrations at the time of capture. In this case, Mg also followed the same profile. Conversely, specimen GMNH 2600017.B from Plash Island shows an O profile indicating winter capture (Figure 5); again, strontium behaves as predicted, with a high 401 value at the terminal edge of the otolith. As mentioned above, it is this strontium effect that is 402 pulling the specimens apart on Axis 1 in Figure 2, suggesting that seasonality is reflected in the 403 multivariate analysis as well. However, as is often the case with O isotopes, (Reitz et al. 2013), 404 clear elemental seasonal profiles were not visible on the majority of specimens analyzed via LA405 ICP-MS. Until more control over the many variables that can affect results are obtained, we will 406 remain uncertain as to why this is the case.

407

408

\section{Conclusions}

409

While some apparently excellent results have been achieved in the chemical fingerprinting 410 of both freshwater and saltwater fish otoliths using LA-ICP-MS, there is, in fact, great variability 411 in success rates for source characterization reported in the literature, from $100 \%$ (e.g., Ludsin et 412 al. 2006) to as low as 50\% (e.g., Thorrold et al. 1998). The causes of this variability remain 413 unclear, but it is likely that there are many contributing factors in any particular study. The 414 caveat for archaeologists is that adoption of elemental analysis of otoliths via LA-ICP-MS (or by 415 any other method) must proceed with extreme caution while work on modern samples helps 416 clarify how data should best be obtained and interpreted and while sources of analytical noise 417 peculiar to archaeological material are explored.

418 The method does show promise as a way of assessing seasonality, but as relevant data can be 419 obtained via O isotope analysis of otoliths and from other, more traditional, zooarchaeological methods 420 (e.g., assemblage composition, size grading of fish), it is unclear that, even if seasonal signatures can be 421 obtained from trace element analysis, anything of real additional worth can be obtained from the 
422 application of LA-ICP-MS, except perhaps as a cross-check on existing methods. The seasonality

423 question will not in any case ultimately be settled by site-by-site judgments, as sedentariness

424 itself likely represents a shift in the scale of selection (Dunnell 1996) given that

425 obtaining/processing/circulating resources doubtless required different mechanisms than were in

426 place for mobile groups. As Reitz et al. (2013) discuss, we are at a point where variability in

427 how, when and where such selection took place can be addressed and hopefully, from an

428 evolutionary perspective, explained. Whether LA-ICP-MS analysis of otoliths can routinely

429 contribute in this regard via seasonality determination has not yet been demonstrated with

430 certainty.

431 A related promise, mostly unrealized at this point, is to obtain chemical data representing the place

432 of capture. If local chemical signatures can be established (see below), then chemical "outliers” become

433 important as likely representing different water bodies (e.g., estuaries fed by different rivers) where fish

434 were captured. Such "imports" could represent either the actual catchment being exploited by Native

435 fishers or foodstuffs brought to a site for communal gatherings, either situation being enabled by the use

436 of watercraft for transport (Ames 2002). Although finding such patterns, if they exist, would entail

437 analyzing large numbers of otoliths, choosing samples from particular kinds of archaeological contexts

438 (e.g., midden vs. mound-side debris) would be an obvious tactic to employ. Establishing spatial links

439 across settlement patterns via otolith chemistry or isotopic composition is one way to begin exploring

440 variability in settlement patterns across space and through time. One way forward may be to focus less on

441 divalent cations and more on stable isotopes and those elements that do not substitute for Ca in otoliths

442 (e.g., Andrus and Thompson 2011). When linked with O isotope and morphometrics (Disspain 2010;

443 Disspain, Ulm, and Gillanders 2015; Disspain, Wilson, and Gillanders 2012) such data may be used

444 formally to establish site catchment, which would be a very powerful tool for exploring the evolution of

445 sedentary settlement patterns, for example. 
An interesting question is whether archaeological otoliths have applied value; e.g., to look

447 for shifts in fish ranges or natal areas over “deep” time. A problem in this regard is in

448 determining the expected "local” signature of the otolith core. In many, if not most, cases

modern fish cannot be used to establish expectations for archaeological otolith chemistry due to

450 water pollution and other changes in external conditions. Size grading of archaeological samples

451 can indicate the life stage at which fish were captured, but if small (young) fish are assumed to

452 be "local," their use in chemical characterization becomes a circular argument, given that they

453 could have been captured elsewhere and transported to the site. Also, growth rates between past

454 and modern fish may have been significantly different (Andrews et al. 2003; Van Neer et al.

455 2002), so modern analogs must be approached with great caution. To provide such baseline data,

456 it will be necessary to analyze large numbers of otoliths of target fish species that reasonably can

457 be assumed to have been locally obtained at an early life stage based on size and habit, then

458 removing statistical outliers to establish expected local elemental ranges. As is always the case in

459 environmental archaeology, however, researchers must be aware of, and try to test for,

460 complications arising from equifinality issues. And even with such work, the pollution problem

461 still persists in reverse: that is, there can be no direct comparison of archaeological to modern

462 specimens; rather, one would have to look at ranges via archaeological specimens and compare

463 them to ranges established via modern specimens to look for change over time. This means, of

464 course, that archaeological specimens representing off-shore seasonal signatures would have to

465 be present in archaeological deposits as well. At a broad level, simple comparisons of

466 archaeological vs. modern otoliths, either as whole-samples or via LA-ICP-MS, can at least be

467 informative where the scale of modern pollution (e.g., Ba uptake) is concerned, and such 
468 comparisons also may yield information of interest for paleoclimatologists (Andrus and Crowe 469 2002:292).

470

471

Acknowledgements

472

We thank Elizabeth Reitz, Greg Waskelkov, Fred Andrus, and other participants in the

473 Woodland Seasonality on the Northern Coast of the Gulf of Mexico project. Funding for that 474 project, which included LA-ICP-MS analysis of otoliths at Mississippi State University, was 475 provided by the National Science Foundation (Award \# BCS 1026167).

476

\section{References}

478 Ames, K.M. 2002. Going by boat: the forager-collector continuum at sea. In: Fitzhugh, B., Habu, 479 J. (Eds.), Beyond Foraging and Collecting: Evolutionary Change in Hunter-Gatherer Settlement. Kluwer Academic/Plenum Press, New York, pp. 19-52.

481

482

Andrews, A.H., Gobalet, K.W., Jones, T.L. 2003. Reliability assessment of season-of-capture determination from archaeological otoliths. Bulletin of the Southern California Academy of Sciences 102(2):66-78.

484

Andrus, C.F.T., Crowe, D.E. 2002. Alteration of otolith aragonite: effects of prehistoric cooking 485 methods on otolith chemistry. Journal of Archaeological Science 29, 291-299.

486

Andrus., C.F.T., Thompson, V.D.. 2011. Determining the habitats of mollusk collection at the Sapelo Island shell ring complex, Georgia, USA using oxygen isotope sclerochronology. Journal of Archaeological Science 39, 215-228.

Barnett-Johnson, R., Ramos, F.C., Grimes, C.B., MacFarlane, R.B. 2005. Validation of Sr 490 isotopes in otoliths by Laser Ablation Multicollector Inductively Coupled Plasma Mass 
Spectrometry (LA-MC-ICPMS): opening avenues in fisheries science applications. Canadian Journal of Fisheries and Aquatic Science 62, 2425-2430.

Bath, G.E., Thorrold, S.R., Jones, C.M., Campana, S.E., McLaren, J.W., Lam, J.W.H. 2000. Strontium and barium uptake in aragonitic otoliths of marine fish. Geochimica et Cosmochimica Acta 64, 1705-1714.

Campana, S.E. 1999. Chemistry and composition of fish otoliths: pathways, mechanisms and 497 applications. Marine Ecology Progress Series 188, 263-297.

Campana, S.E., Fowler, A.J., Jones, C.M. 1994. Otolith elemental fingerprinting for stock identification of Atlantic cod (Gadus morhua) using Laser Ablation ICPMS. Canadian Journal of Fisheries and Aquatic Science 51, 1942-1950.

Chang, M.-Y., Geffen, A.J., Kesler, J., Dundas, S.H., FishPopTrace Consortium, Maes, G.E., 502 2012. The effect of ablation pattern on LA-ICPMS analysis of otolith element composition in hake, Merluccius merluccius. Environmental Biology of Fishes 95, 509-520.

Chen, W., Al-Husaini, M., Beech, M., Al-Enezi, K., Rajab, S., Husain, H. 2011. Discriminant analysis as a tool to identify catfish (Ariidae) species of the excavated archaeological otoliths. Environmental Fish Biology 90, 287-200.

Colaninno, C.E. 2012. Evaluating $\delta^{18} \mathrm{O}$ profiles for hardhead catfish and Atlantic croaker otoliths as a method of determining seasonal use of fishes. In: Reitz, E.J., Quitmyer, I.R., Thomas, D.H. (Eds.), Seasonality and Mobility along the Georgia Bight. Anthropological Papers of the American Museum of Natural History 97, pp. 83-101.

Collins, J.D. 2012. Assessing mussel shell diagenesis in the modern vadose zone at Lyon’s Bluff (22OK520), northeast Mississippi. Journal of Archaeological Science 39, 3694-3705. 
513 Cook, G.S. 2011. Changes in otolith microchemistry over a protracted spawning season influence assignment of natal origin. Inter-Research Marine Ecology Progress Series 423, 197-209.

Degens, E.T., Deuser, W.G., Haedrich, R.L. 1969. Molecular structure and composition of fish otoliths. Marine Biology 2, 105-113.

Disspain, M. 2010. Using archaeological otoliths to determine palaeoenvironmental change and Ngarrindjeri resource use in the Coorong and Lower Murray, South Australia. Thesis

Disspain, M.C.F., Ulm, S., Gillanders, B.M. 2015. Otoliths in archaeology: methods, applications and future prospects. Journal of Archaeological Science: Reports (2015), http://dx.doi.org/10.1016/j.jasrep2015.05.012

Disspain, M.C.F., Wilson, C.J., Gillanders, B.M. 2012. Morphological and chemical analysis of archaeological fish otoliths from the lower Murray River, South Australia. Archaeology in Oceania 47:141-150.

Dunnell, R.C. 1996. Natural selection, scale, and cultural evolution-some preliminary considerations. In: O’Brien, M.J., Lyman, R.L. (Eds.), Evolutionary Archaeology. University of Utah Press, Salt Lake City, pp. 24-29.

Elsdon, T.S., Gillanders, B.M. 2003. Reconstructing migratory patterns of fish based on environmental influences on otolith chemistry. Reviews in Fish Biology and Fisheries 13, 219-235.

Gabitov, R.I., Gagnon, A.C., Guan, Y., Eiler, J.M., Adkins, J.F. 2013. Accurate Mg/Ca, Sr/Ca, and $\mathrm{Ba} / \mathrm{Ca}$ ratios measurements in carbonates by SIMS and NanoSIMS and an assessment of heterogeneity in common calcium carbonate standards. Chemical Geology 356, 94-108. 
Gaetani, G.A., Cohen, A.L. 2006. Element partitioning during precipitation of aragonite from seawater: A framework for understanding paleoproxies. Geochimica et Cosmochimica Acta 70, 4617-4634.

Hale, R., Swearer, S. 2008. Otolith microstructural and microchemical changes associated with settlement in the diadromous fish Galaxias maculatus. Marine Ecology Progress Series 354, 229-235.

Hamilton, S.L., Warner, R.R. 2009. Otolith barium profiles verify the timing of settlement in a coral reef fish. Marine Ecology Progress Series 385, 237-244.

Hoff, G.R., Logan, D.J., Markle, D.F. 1997. Otolith morphology and increment validation in young Lost River and shortnose suckers. Transactions of the American Fisheries Society 126, 488-494.

Jackson, D.A. 1993. Multivariate analysis of benthic invertebrate communities: the implications of choosing particular data standardizations, measures of association, and ordination methods. Hydrobiologia 268, 9-26.

Jones, C.M., Chen, Z. 2003. New techniques for sampling larval and juvenile fish otoliths for trace-element analysis with Laser-Ablation Sector-Field Inductively-Coupled-Plasma Mass Spectrometry (SF-ICP-MS). In: Browman, H.I., Skiftesvik, A.B. (Eds.), The Big Fish Bang: Proceedings of the $26^{\text {th }}$ Annual Larval Fish Conference. Institute of Marine Research, Bergen, Norway, pp. 431-443.

Kalish, J.M. 1989. Otolith microchemistry: validation of the effects of physiology, age and environment on otolith composition. Journal of Experimental Marine Biology and Ecology 132, 151-178. 
Kalish, J.M. 1991. Determinants of otolith chemistry: seasonal variation in in the composition of blood plasma, endolymph and otoliths of bearded rock cod Pseudophycis barbatus. Marine Ecology Progress Series 74, 137-159.

Legendre, P., Birks, H.J.B. 2012. From classical to canonical ordination. In: Birks, H.J.B., Lotter, A.F., Juggins, S., Smol, J.P. (Eds.), Tracking Environmental Change using Lake Sediments, Volume 5: Data Handling and Numerical Techniques. Spinger, Dordrecht, The Netherlands, pp. 201-248.

López-Duarte, P., Carson, H.S., Cook, G.S., Fodrie, F.J., Becker, B.J., DiBacco, C., Levin, L.A. 2012. What controls connectivity? An empirical, multi-species approach. Integrative and Comparative Biology 52, 511-524.

Ludsin, S.A., Fryer, B.J., Gagnon, J.E. 2006. Comparison of solution-based versus Laser Ablation Inductively Coupled Plasma Mass Spectrometry for analysis of larval fish otolith microelemental composition. Transactions of the American Fisheries Society 135, 218-231.

McCune, B. Mefford, M.J. 2011. PC-ORD. Multivariate Analysis of Ecological Data. Version 6.08. MjM Software, Gleneden Beach, Oregon.

Mendoza-Carranza, M. 2003. The feeding habits of gafftopsail catfish Bagre marinus (Ariidae) in Paraíso Coast, Tobasco, Mexico. Hídrobiológica 13, 119-126.

Mugiya, Y., Satoh, C. 1995. Strontium-calcium ratios change corresponding to microincrements in otoliths of goldfish Carassius auratus. Fisheries Science 61, 361-362.

Nance, C.R., de Leeuw, J., Weigand, P.C., Prado, K., Verity, D.S. 2013. Correspondence Analysis and West Mexico Archaeology. University of New Mexico Press, Albuquerque.

Oksanen, J. 2013. Multivariate Analysis of Ecological Communities in R: Vegan Tutorial. Cc.oulu.fi/ jarioska/opetus/metodi/vegantutor.pdf. Accessed May 1, 2015. 
Peacock, E. 2002. Shellfish use during the Woodland period in the Middle South. In: Anderson, D.G., Mainfort, R. (Eds.), The Woodland Southeast. The University of Alabama Press, Tuscaloosa, pp. 444-460.

Peacock, E., Palmer, R.A., Xia, Y., Bacon-Schulte, W., Carlock, B., Smith, J. 2010. Chemical sourcing of a prehistoric freshwater shell artifact using Laser Ablation-Inductively Coupled Plasma-Mass Spectrometry. Archaeology of Eastern North America 38, 91-99.

Pontual, H., Lagardère, F.L., Troadec, H., Batel, A., Désaunay, Y., Koutsikopoulos, C. 2000. Otoliths imprinting of sole (Solea solea) from the Bay of Biscay: a tool to discriminate individuals from nursery origins? Oceanologica Acta 23, 497-513.

Proctor, C.H., Thresher, R.E. 1998. Effects of specimen handling and otolith preparation on concentration of elements in fish otoliths. Marine Biology 131, 681-694.

Ramenofsky, A.F., Neiman, F., Piere, C.D. 2009. Measuring time, population, and residential mobility from the surface at San Marcos Pueblo, north central New Mexico. American Antiquity 74, 505-530.

Ramsay, A.L., Milner, N.J., Hughes, R.N., McCarthy, I.D. 2011. Comparison of the performance of scale and otolith microchemistry as fisheries research tools in a small upland catchment. Canadian Journal of Fisheries and Aquatic Science 68, 823-833.

Reitz, E.J., Hadden, C.S., Little, M.E., Waselkov, G.A., C. Andrus, C.F.T., Peacock, E. 2013. Final Project Report: Woodland Seasonality on the Northern Coast of the Gulf of Mexico. Final technical report submitted to the National Science Foundation for project title, “Collaborative Research Project: Woodland Subsistence Seasonality on the Northern Gulf Coast,” Award \# BCS 1026167. 
Resano, M., García-Ruiz, E., Vanhaecke, R. 2009. Laser Ablation-Inductively Coupled Plasma Mass Spectrometry in archaeometric research. Mass Spectrometry Reviews. DOI 10.1002/mas:1-24.

Rossi, V. 2010. Ordination Methods for Analyzing Ecological Data. Course materials for CIRAD-UMR Ecologie de Forêts de Guyane, Master 2 - Ecologie des Forêts Tropicale. AgroParis Tech - Université Antilles-Guyanne, Kourou, November 2010. vrossi.free.fr/DONNEES/ ordination.pdf, accessed May 1, 2015.

Saunders, J.W., Mandel, R.D., Sampson, C.G., Allen, C.M., Allen, E.T., Bush, D.A., Feathers, J.K., Gremillion, K.J., Hallmark, C.T., Jackson, H.E., Johnson, J.K., Jones, R., Saucier, R.T., Stringer, G.L., Vidrine, M.F. 2005. Watson Brake, a Middle Archaic mound complex in northeast Louisiana. American Antiquity 70, 631-668.

Smith, K.Y., Neiman, F.D. 2007. Frequency seriation, correspondence analysis, and Woodland period ceramic assemblage variation in the Deep South. Southeastern Archaeology 26, 4772.

Speakman, R.J., Neff, H. (Eds.). 2005. Laser Ablation-ICP-MS in Archaeological Research. University of New Mexico Press, Albuquerque.

Swearer, S.E. 2000. Self-Recruitment in Coral-Reef Fish Populations. Unpublished PhD. dissertation, University of California, Santa Barbara, California.

Thorrold, S.R., Jones, C.M., Swart, P.K., Targett, T.E. 1998. Accurate classification of juvenile weakfish Cynoscion regalis to estuarine nursery areas based on chemical signatures in otoliths. Marine Ecology Progress Series 173, 253-265.

Thresher, R.E., Proctor, C.H., Gunn, J.S., Harrowfield, I.R. 1994. An evaluation of electronprobe microanalysis of otoliths for stock delineation and identification of nursery areas in a 
southern temperate groundfish, Nemadactylus macropterus. U.S. Fisheries Bulletin 92, 817-

627 840.

628 Valamoti, S.M., Jones, G. 2003. Plant diversity and storage at Mandalo, Macedonia, Greece:

629 archaeobotanical evidence from the Final Neolithic and Early Bronze Age. The Annual of 630 the British School at Athens 98, 1-35.

631 Van Neer, W., Ervynck, A., Bolle, L.J., Millner, R.S., Rijnsdorp, A.D. 2002. Fish otoliths and 632 their relevance to archaeology: an analysis of medieval, post-medieval, and recent material 633 of plaice, cod and haddock from the North Sea. Environmental Archaeology 7:61-76.

634 Weber, P.K., Hutcheon, I.D., McKeegan, K.D., Ingram, B.L. 2002. Otolith sulfur isotope method 635 to reconstruct salmon (Oncorhynchus tshawytscha) life history. Canadian Journal of $636 \quad$ Fisheries and Aquatic Science 59, 587-591. 
Figure 1. Location of Plash Island and Bayou St. John sites. From Reitz et al. (2013).

Figure 2. Ordination of all otolith specimens tested from Plash Island and Bayou St. John sites using Sr, Na, Mg and Ba.

Figure 3. Ordination of specimens of Ariopsis felis from Plash Island and Bayou St. John sites using Sr, $\mathrm{Na}, \mathrm{Mg}$ and $\mathrm{Ba}$.

Figure 4. Oxygen isotope ( $\delta^{18} \mathrm{O}, \%$ ), $\mathrm{Mg} / \mathrm{Ca}$, and Sr/Ca curves from otolith GMNH 2560215.A from the Bayou St. John site, representing summer capture. The X-axis represents successive micromill tracks/laser rasters beginning (L) at $50 \mu \mathrm{m}$ from the edge of the otolith. Figure 5. Oxygen isotope, Mg/Ca, and Sr/Ca curves from otolith GMNH 2600017.B from the Plash Island site, indicating winter capture. The X-axis represents successive micromill tracks/laser rasters beginning (L) at $50 \mu \mathrm{m}$ from the edge of the otolith. 


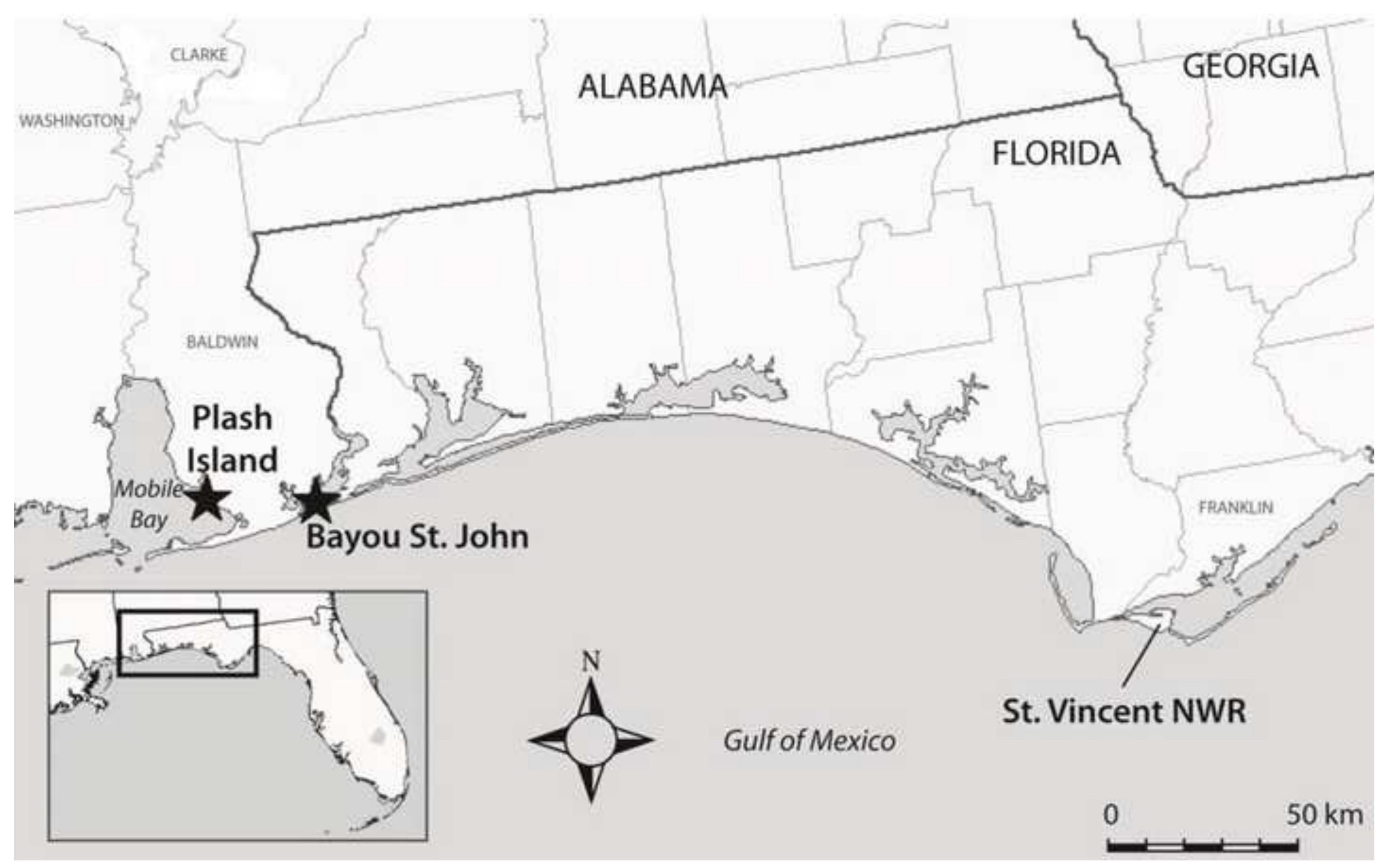

$50 \mathrm{~km}$ 
PI A. felis

\begin{tabular}{l|} 
A \\
$x$ \\
$i$ \\
s \\
2
\end{tabular} Axis 1
BStJ A. felis

BStJ Ariidae ${ }^{\wedge}$

PI Ariidae

$\triangle \quad \mathrm{PI}$ B. marinus

BStJ B. marinus ${ }^{\wedge}$

PI A. felis

PI A. felis 


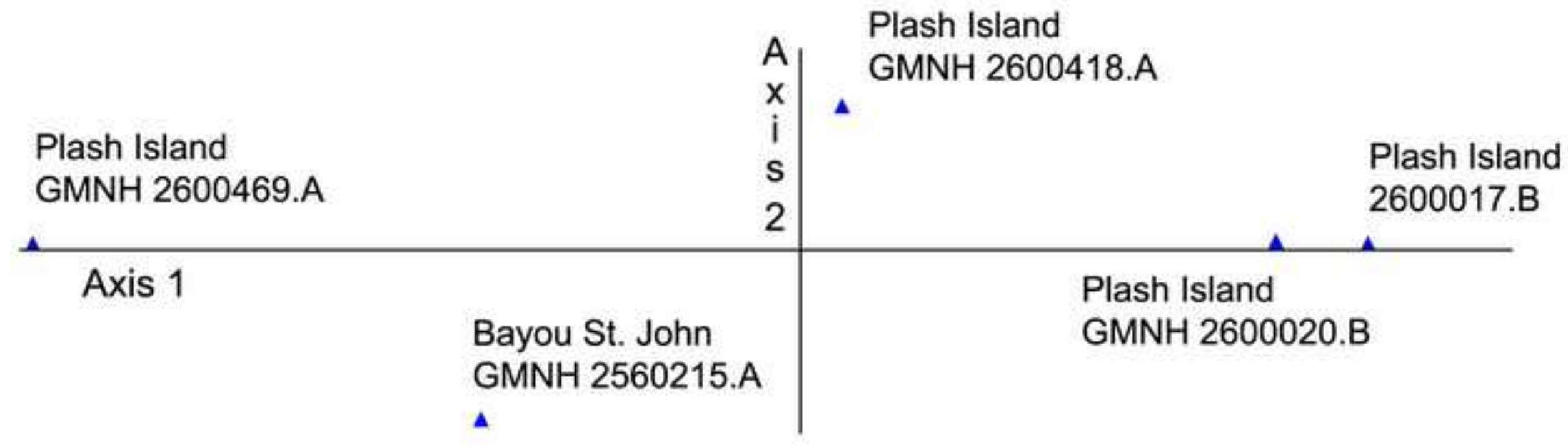


Figure 4
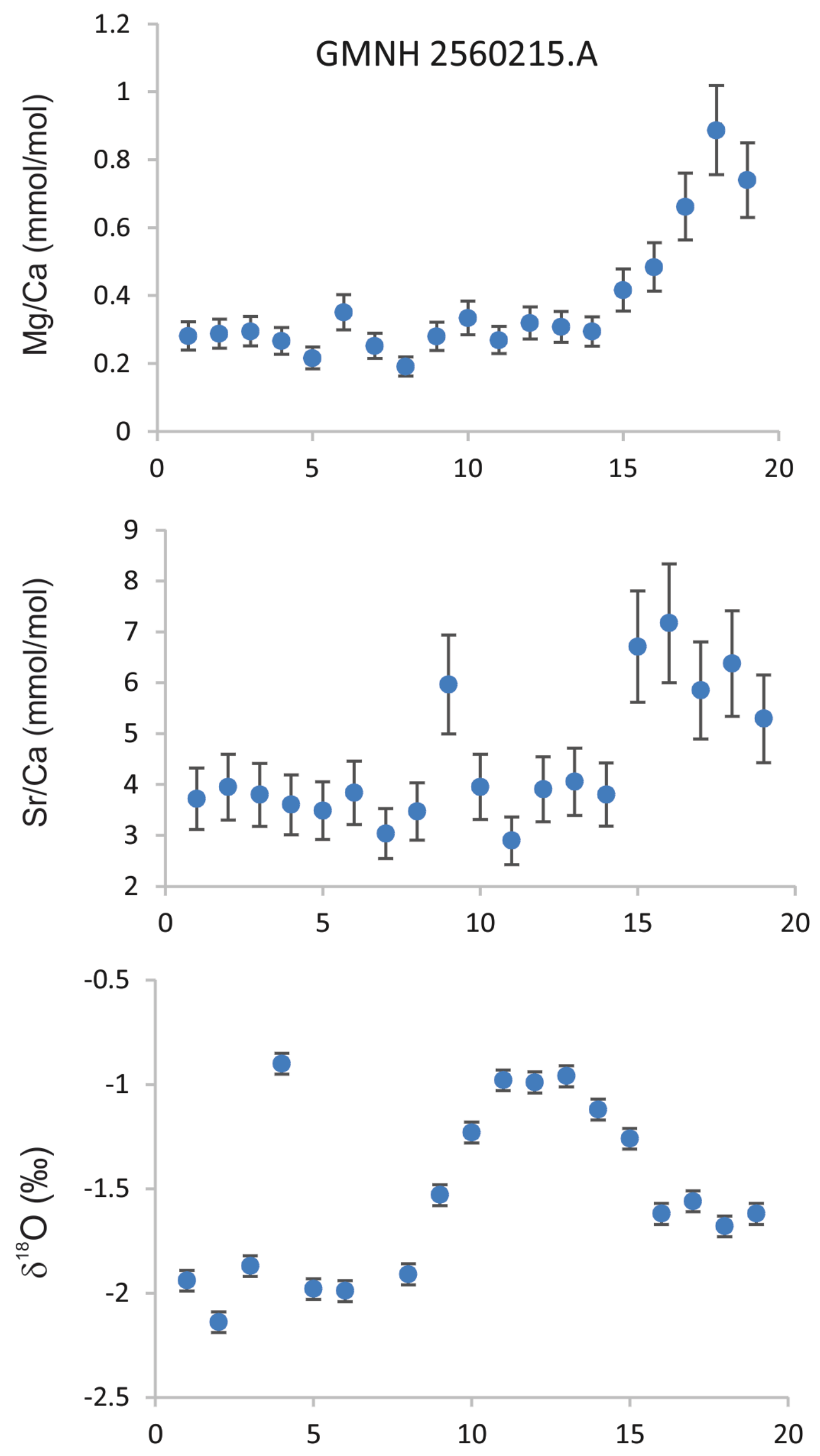
Figure 5
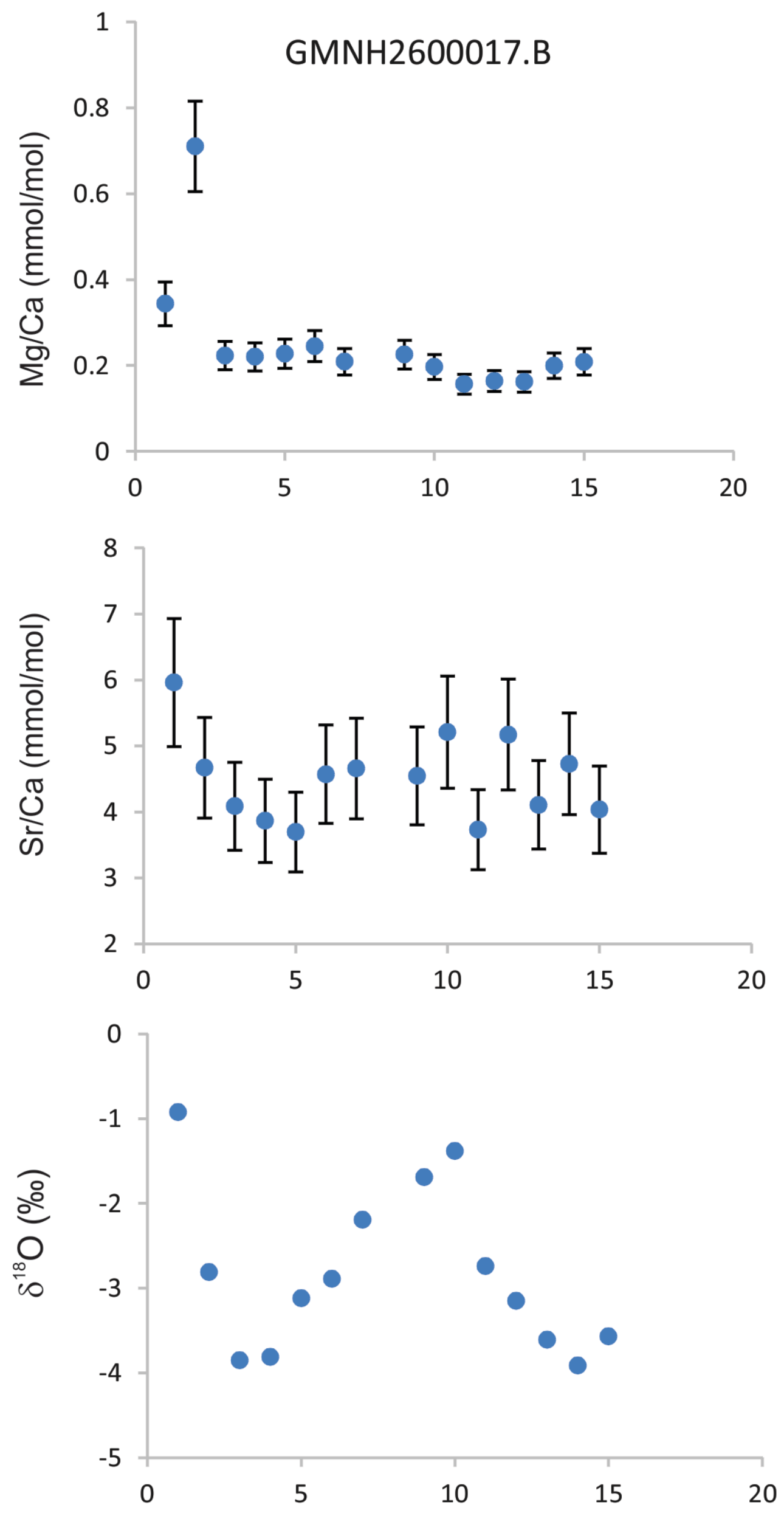